\title{
Exploration on Talents Training Cultivation mode of Electronic Information and Communication Major Yu-Feng GAO ${ }^{a}$, Zhong-Li WANG ${ }^{b^{*}}$ and Lu ZHANG ${ }^{\mathrm{c}}$ College of Electrical and Information Engineering, Beihua University, Jilin, China a164085443@qq.com, ${ }^{b}$ wangzhongli@beihua.edu.cn,,2509923041@qq.com \\ ${ }^{*}$ Corresponding author: Zhong-Li WANG
}

Keywords: Talent training model; "Base + project + team" personnel training mode; Application-Oriented major;

\begin{abstract}
This paper explores engineering ability training from research oriented undergraduate to application oriented Undergraduate, combined with the development of Beihua University electronic information and communication major, Explore and practice main mode of the "base + project + team" training mode. Combining production with education, professional tutor and international education combined mode, highlighting the importance of talents training in Application-Oriented major.
\end{abstract}

\section{Introduction}

February 26, 2014, Premier Li Keqiang chaired a State Council executive meeting, the deployment to accelerating the development of modern vocational education, proposed to "guide a number of ordinary undergraduate universities to application of technological transformation." ${ }^{[1]}$ The past two years, discussion on the reform of the transformation from teaching to application of technical personnel training mode in local colleges and universities in full swing. Application oriented undergraduate talent training should focus on engineering and technical personnel, and vocational skills to focus on the training of vocational skills. Therefore, the application oriented undergraduate students should pay attention to the systematic cultivation of students' knowledge; the students' knowledge should pay attention to the depth and breadth. In order to avoid the convergence with Higher Vocational Colleges, through the development of developed countries, analysis the different with the research universities and vocational colleges, such as "the characteristics of the German University of Applied Technology, ${ }^{[2]}$ " "dual system ", ${ }^{[3]}$ " order mode " and " post practice mode ${ }^{[4]}$, combined with our own characteristics, formed in line with the professional development of new personnel training mode.

\section{The initial study on training for application technology talents in electronic information and communication major}

November 2015, the major of electronic information and communication first batch Local application oriented Undergraduate University, Beihua University. There is no fundamental difference between the social responsibility and the main differences between the research undergraduate and the applied undergraduate education, and the main differences between the two are embodied in the different orientation and development goals. In the process of the transformation from research to application, we must first focus on the orientation of local colleges and universities to serve the local economy. To build a distinctive point of application-oriented professional goal, hand in hand with international famous universities, domestic famous enterprises, and innovative teaching mode, let the students have the following skills: technology and innovation, humanities and moral character, professional knowledge and Professional accomplishment, communication and teamwork, International vision and communication skills, etc. 


\section{1 "Base + project + team" personnel training mode}

Application technology undergraduate is the training of technology-applied talents; measure is to look at the students' technological innovation and application capabilities. Therefore, with the goal of training the application oriented talents and high skilled, to achieve knowledge input, ability to export, have academic education and engineering ability training “dual talent training”. In addition to setting a diversified curriculum model, teaching methods to be a breakthrough. To carry out the teaching principle of "students' participation, diverse forms, comprehensive utilization, scientific research infiltration, combination of learning, classroom based, extracurricular supplementary". Encourage students to actively participate in teaching practice, to learn to use combination. Teachers make full use of multimedia, network and other modern educational technology, comprehensive use of case based, situational, speech, debate, and other teaching methods, will be extended out of the classroom. And actively encourage teachers to explore with the characteristics of the subject of "scientific research infiltration" and other inquiry-teaching mode. Integrating scientific research thinking, research methods, experimental design and scientific and technological training into the teaching process. This combination of study, ability of all-round, open type teaching mode can not only make the students way of thinking, learning and application of knowledge to obtain the full development, but also can promote students' innovative quality and full development of personality. In order to ensure that the targeted research penetration mode fall to real point, we explored the training mode of "base + project + team", which runs through the university for four years, from the freshman entrance of knowledge education to the export of engineering ability to the senior four. The model is shown as follows.

\section{Engineering ability training of ICT platform}

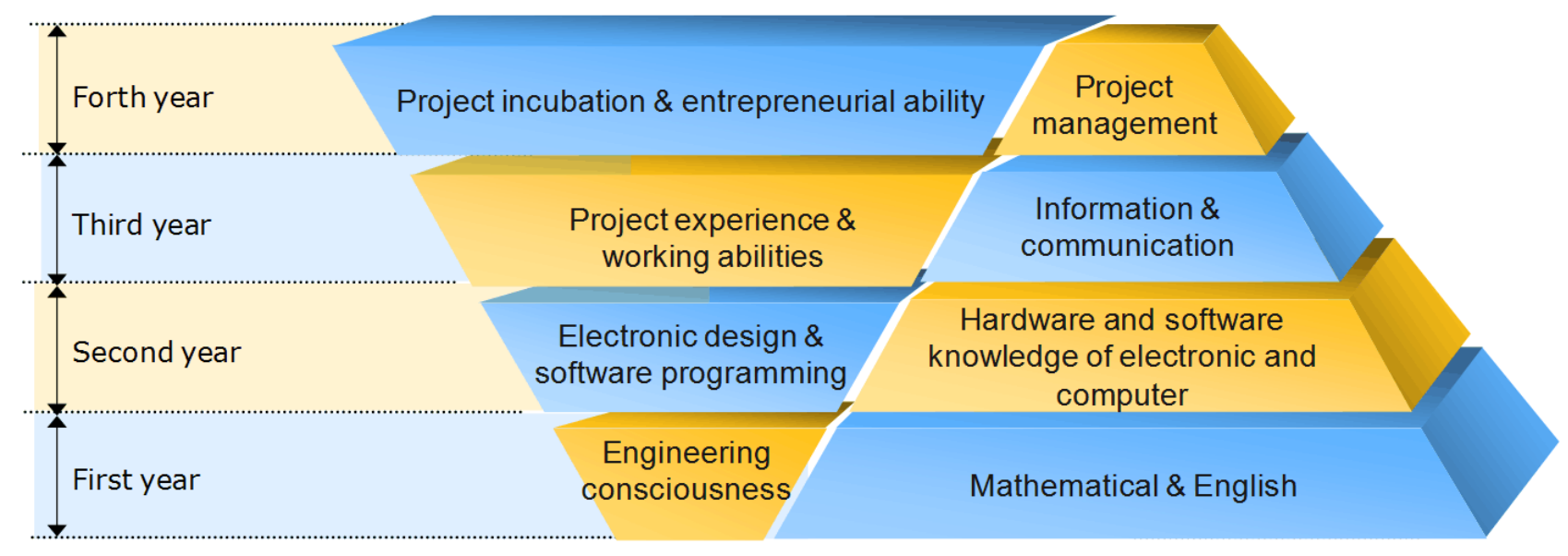

Academic education

Fig.1."Base + project + team" personnel training mode

The innovation base of university is an important part of the current engineering education, and it is also an important to improve the quality and comprehensive quality of engineering education. Our three transformation major set up six innovation bases, and students are the main activities on innovation base. Therefore, the base of the organization, operation, management system, teaching content are mainly by the students, through the effective organization and guidance of teachers to achieve self-design, self-organization, funds, places and time all to the students, so that students from passive to active learning ${ }^{[5]}$.

When the freshman enrollment, choice into which base freely, guided by the base of the simple electronic design, $\mathrm{C}$ language learning, to develop their engineering awareness. The main class is foreign languages, advanced mathematics and university physics as academic education. Sophomore, according to the interests of students, divided into hardware and software in two directions. Hardware to SCM-based, high-level programming to the main software, by participating in the national college 
students electronic competitions, software competitions to improve practical ability. Diploma education to electronic, computer professional basic courses and pass College English Test Band 4. The National Undergraduate Electronic Design Contest is one of the college students' subject contest co sponsored by Ministry of education and the Ministry of industry and information technology, is for the masses of students of science and technology activities, aims to promote the reform of colleges and universities to promote the information and electronic curriculum system and curriculum. The sophomore students participate in the university students' electronic competition; combining with the knowledge and practice ability, improve the practical ability, team cooperation ability and writing level. It also promotes the teaching of the course, the teaching reform and the construction of the laboratory.

Junior is mainly responsible for bringing freshman and sophomore students to jointly declare the innovation and entrepreneurship projects. The National College Students' innovation and entrepreneurship training program, the purpose is to promote the concept of higher education to change the concept of education, the reform of personnel training mode, strengthen the ability of innovation and entrepreneurship training, enhancing university students' innovation ability and the innovation on the basis of entrepreneurial ability, to cultivate high-level innovative talents to the construction of an innovative country. In the process of innovation in the training program, and to solve the problems related knowledge through experiment and practice thinking, the problem solving and creative learning will stand up, to apply theoretical knowledge to specific projects, to find a reasonable solution to the. The project as the carrier, to mobilize the initiative, enthusiasm and creativity of students, to stimulate students' innovative thinking and innovative awareness, to master the thinking, problem-solving methods to improve innovation and practical ability.

Senior student who will graduated do the project incubation. Through the local government and the school incubator, the establishment of College Students' innovation and entrepreneurship fund, for the students' entrepreneurial projects transplanted to the incubator for review, approval and management. In this process, students simulate the process of project bidding and tendering, which is more close to the social demand. When mature entrepreneurial projects gradually into the community, the mentor to support the project management team, so that they grow up.

"Innovation and entrepreneurship" education will throughout the whole process of university education. Due to the limited number of students participating in the national level innovation projects, the professional focus on practical ability training and various forms of applied knowledge and skills competitions, highlighting the practical ability, application of knowledge and skills training. Through the model of "base + project + team", the students' abilities of information acquisition and expression, self - learning ability, practical ability, creative thinking ability, system cognitive ability, system development ability and team cooperation ability are cultivated.

\subsection{Combination of industry and teaching, Talents training integrating with social needs}

On the way of running a school, the combination of industry, study and research and the education of applied Undergraduate cooperation is the fundamental way of teaching reform. Combination of industry and Teaching is an effective way to realize comprehensive quality personnel training and improve teaching quality. Through the combination of industry and learning, students can be applied the class learning to the operation, to achieve the theory of sublimation and skills of internalization, so as to truly master the knowledge. At the same time, the school can view the quality of school management, through the theoretical study and practical operation results, and constantly adjust the curriculum, class arrangements, teaching materials, etc., to achieve effective teaching reform, improve school quality. Communication Engineering through the declaration of "2015-2020 Ministry of Education - ZTE ICT production base integration of innovation and education institutions" project, to achieve school-enterprise build. And with China Mobile, China Telecom Group to establish a school-enterprise cooperation, through the integration of resources, hire the engineers who work in the company's production line with rich practical experience of invited to teach, the formation of cooperative training model, through cooperation, understanding business needs, adjust the personnel 
training objectives, a clear quality requirements of personnel training, improve the employment level of employment of students and development capacity.

\subsection{Equipped with professional tutor, tracking professional guidance}

At present, the majority of students' management and employment guidance are the work of counselors. As the major of counselors do not as same as students, so they can't effectively guide students in professional knowledge and innovation. Transformation major are focus more on quality education and career planning education. In the application of personnel training, student learning, life, thinking, psychology, employment and other aspects of guidance and education is essential, Professional tutor in the process of training students has a significant importance can not be ignored. We should carry out the mentoring system for undergraduates during the university period, so as to build up the moral education system with the aim of cultivating people. In order to build up the whole staff, the whole process of education, comprehensive education, people-oriented moral education work system as the main line, improve the level of school moral education, and promote the quality of Education $^{[6]}$. Since 2015, our university chooses a strong sense of responsibility, professional quality teachers as professional tutor; they work with full-time counselor together. Professional tutor provide students with scientific and technological innovation platform, counseling students to participate in scientific research, scientific and technological competitions, training students 'practical ability and scientific and technological innovation ability; to improve the students' ability to innovate; to provide conditions and guide students to professional social practice; to guide students to graduate design and graduation thesis; guide students to graduate or employment. Professional tutors not only guide the study and research symbols, but also a fresh person with blood, most professional tutors distinctive personality, sincere feelings, behavior lofty, long-term get along with the students in academic and human get nurtured.

\subsection{Open international school concept, and comprehensively enhance the school brand image}

In the course of personnel training, the concept of internationalization has been established. In recent years, the depth and breadth of the open education have been expanded, and international education has been adopted for international students through a wide range of international exchanges. Build a broad platform. According to our own needs and the transformation of professional school of international studies, we approached several foreign universities. The principle of selecting cooperation in running schools is to require the curriculum system approach, the course similarity is high, and the teaching level of the teachers is good. ${ }^{[8]}$ We are talk with Cornell University in the United States currently, intends to establish a cooperative education international class. Cornell University curriculum system and ours are on the similarity of $45 \%$. Through cooperation in running schools enhance the ability of cross-cultural communication, so as to enhance the students' ability of cross-cultural communication. Base on the international class students can master both the knowledge and skills of electronic information and proficiency in English expression and communication. to cultivate talents in the field of world communication.

\section{Conclusions}

The existence of a discipline, not only lies in its use value, but also in its social services function. Electronic information undergraduate majors in the world of science and technology innovation is the leading professional, in order to eternal vitality and vitality, it is necessary to transform their training mode. This paper discusses the transformation of the talent cultivation mode from four aspects: training objectives, talent training mode of "base + project + team", professional tutor system and international education, hoping to be a reformer of this specialty. Hope to provide a little reference for the transformation of the professional reformers to its personnel-training mode, to promote the vigorous development of electronic information undergraduate professional. 


\section{References}

[1] Zhuang Xi true. Ordinary undergraduate institutions in transition: why turn, what turn, how to turn. [J] Chinese vocational and technical education, 2014 (21).

[2] Zonglian. University of Applied Sciences in Germany, the characteristics of our reference and inspiration [J]. Beijing Financial and Trade Vocational College, 2012 (28).

[3] HAN Shu-ming. Practice of Mechatronics Technology Talents Training Model Based on "Dual System" in Higher Vocational Education, Vocational and Technical Education 2012 (35).

[4] Shi Haixin. Undergraduate colleges of transformation and application of personnel training mode. Journal of Qinzhou University, 2013 (8).

[5] Zhang Zheng. Research on the training mode of innovative practice ability of college students based on innovation base as the platform. Science and technology entrepreneurship, 2016 (9).

[6] Tan Caiyou. Class tutor in the significance of the University, the scientific era .2013 (1).

[7] Chen Qiang, Lu Xiaoming. The innovation education of College Students' Entrepreneurship. Intelligence.2014 (17).

[8] Fan Fuchun, Wang Jinquan. Investigation and Research on the current situation of Chinese foreign cooperative education in the application oriented Universities. Teaching research.2011 